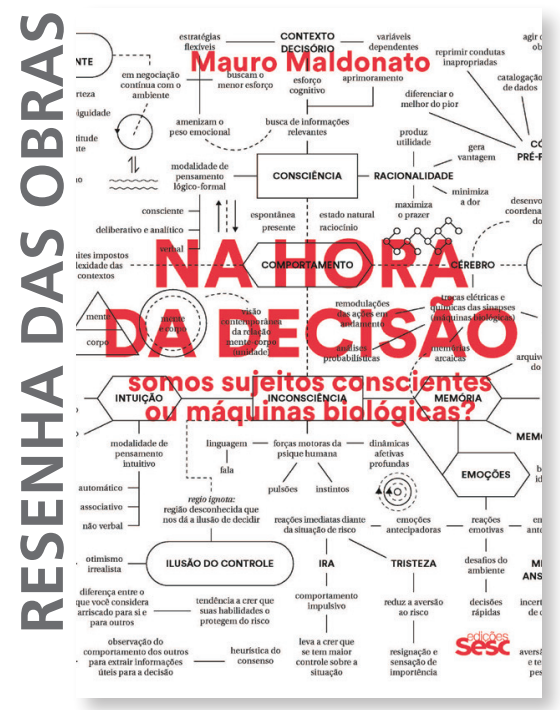

MALDONATO, Mauro. Na hora da decisão: somos seres conscientes ou máquinas biológicas? São Paulo: Edições Sesc São Paulo, 2017.

Gostamos de nos considerar máquinas pensantes, certas de ter tudo sob controle, e que analisam problemas, avaliam vantagens e desvantagens antes de escolher a melhor solução. Mas estamos realmente certos de que sabemos por que fazemos o que fazemos, ou escolhemos o que escolhemos?'

\title{
Muito além da razão
}

Todos já nos encontramos diante da dificuldade de ter que tomar decisões importantes. Ao longo do tempo, cada um de nós acaba criando estratégias pessoais na busca por assegurar para si uma escolha "racional". Acreditamos que decidir é algo que deve envolver, em primeiríssimo lugar, nosso lado racional, nosso comedimento e equilíbrio. Julgamos que para fugir de decisões aventadas, o melhor seja pensar, ponderar. Há os que coletam o máximo de informações possíveis, procurando desenhar um quadro bem claro da situação, convencidos que estão de que desse modo o desafio poderá ser enfrentado da melhor maneira possível. Bem, tudo isso não passa de ilusão. É o que Mauro Maldonato nos mostra em seu último livro Na hora da decisão: somos atores conscientes ou máquinas biológicas? O título explicita com muita eficácia o objetivo da obra, isto é, procurar dar uma resposta clara à pergunta acima, explorando os territórios daquela "misteriosa presença, aquela região desconhecida que nos guia", o "lado sombrio" da consciência.

Na verdade, o livro todo é um grande desafio que procura delinear limites entre o racional e o irracional, aquilo que nós chamamos de "inconsciente" 
- palavra que Maldonato evita ao longo da obra, apontando que o universo inicialmente desenhado por Freud, embora tenha sido um grande avanço, hoje é um modelo já desgastado e sobretudo insuficiente para a compreensão da realidade assim como agora se nos apresenta. E surge o desafio, a necessidade de forjarmos novos termos - ou melhor, uma definição mais precisa de alguns vocábulos que, ao longo dos anos, têm sido usados para designar coisas muito diferentes, como "mente" e "consciência", por exemplo. Para o autor, a questão é mais ampla do que um simples problema terminológico, pois "trata-se não somente de livrar-se de um autoengano linguístico e conceitual, mas também de desfazer a ilusão de que se está seguindo a natureza, ao passo que se trata da forma mediante a qual a observamos. Somos prisioneiros de uma imagem ambígua".

Ao longo do livro, o autor desmistifica nossa ideia de racionalidade, ilustrando com clareza como nossa segurança quanto à existência de um modelo racional de estampa iluminista - que persiste em nossa imaginação como um farol a nos guiar nos momentos cruciais da decisão - não passa de mera ilusão. Para maior clareza, Maldonato cita Albert Einstein: "A mente intuitiva é um dom sagrado e a mente racional é um criado fiel. Criamos uma sociedade que honra o criado e que esqueceu o sagrado".

Mas como deslindar esse território tão movediço? Se tarefa mínima das neurociências, hoje tão na moda, é identificar uma correlação entre estruturas neurobiológicas e comportamento, é porque tudo que se pôde identificar foram correlações, apenas correlações, justamente. Já que até o momento - e o percurso do autor mostra atenção específica e atualizada para com o tema, que como é fácil depreender, está intimamente relacionado à sua atividade clínica e de pesquisa - as técnicas de imagens cerebrais não conseguiram mostrar processos causais.

Os leitores habituais desse psiquiatra e pensador italiano já conhecem a sua habilidade de tratar de temas altamente complexos de maneira rica e clara mas nunca excessiva -, desenredando significados densos, com argumentos sólidos e bem documentados. Suas abordagens requintadamente críticas, embora de impecável elegância, e que mostram não haver, de sua parte, o menor interesse nas modas passageiras, mas, ao contrário, enorme interesse em apreender na própria essência alguns fenômenos que estão na base de intersecções disciplinares aptas a constituírem caminhos e desvios essenciais para o desenvolvimento das ciências humanas e do pensamento. Traços que denotam muitos anos de estudo e pesquisas sistemáticas, que todavia se mesclam com uma boa dose de experiência, seja ela clínica, seja pessoal. Esse vínculo entre teoria e experiência pessoal é um aspecto valorativo da obra que, especialmente pensando no pobre panorama atual, adquire maior relevância. Até aqui, no entanto, nenhuma surpresa para quem teve a oportunidade de acompanhar a trajetória desenhada pelos trabalhos deste pro- 
fessor da Università degli Studi della Basilicata, Itália. Talvez, num primeiro impacto, o tema, que pode parecer muito circunscrito, e por isso distante de suas abordagens habituais. Mas o que mais chama atenção, aqui, são alguns traços bastante singulares ou, arriscamos a dizer, que representam, afinal, o apuramento de alguma coisa que Maldonato vem desenvolvendo constantemente em suas obras e que alcança plena realização neste volume: o autor se volta para o leitor de outros setores disciplinares, da gestão empresarial ao esporte, ou seja, ao leitor leigo, ao leitor comum e curioso e, em linguagem bastante acessível, comenta temas cientificamente complexos e extremamente delicados de maneira compreensível, que, afinal, nos ajudam a entendermos a nós mesmos e nossa atuação diária em sociedade.

Não é tarefa fácil ter êxito com esse tipo de proposta. Tal êxito, no entanto, é plenamente alcançado por este livro. $\mathrm{O}$ autor procura destrinçar, de maneira sistemática e eficiente, e a partir de diferentes pontos de vista, o fenômeno da decisão. Sua reflexão é progressiva, o que dá ao leitor a impressão de estar acompanhando o pensamento do autor no exato momento em que esse vai sendo elaborado; assim, gradualmente, também o leitor vai se aproximando aos poucos da questão tratada, conseguindo identificar-se com as reflexões do autor, colhendo suas nuances mais sutis. E sutilezas não faltam neste escrito. Contudo, ao sincronizar o próprio ritmo interior com aquele do pensamento do autor, que vai se desdobrando à sua frente, o leitor compartilha da liricidade que aflora vez ou outra e que se consolida em fenômeno coral, capaz de estimular intelecto e sentidos.

Os argumentos de Maldonato são convincentes. De que maneira podemos enfrentar essa "viagem ao longo do arquipélago de ilhas de bordas recortadas e mutáveis, a que chamamos de ação humana"? A despeito do "excesso de credulidade em relação ao poder subversor da ciência" a nossa relação com ela aparenta ser "uma credulidade superior até mesmo àquela do camponês medieval para com o próprio pároco", a ponto de que em alguns ambientes - entre os quais estão incluídas as salas dos tribunais - "acredita-se mais nas neuroimagens do que os próprios neurocientistas fazem": o que Maldonato procura ilustrar é que as neurociências, na realidade, ainda oferecem métodos muito aproximativos ao iludir (e iludindo-se) de que são capazes de apreender aspectos da vida real por meio de registros obtidos de sujeitos fechados numa sala de exames: "Indivíduos obrigados a ficarem deitados de barriga para cima em aparelhos de escaneamento dificilmente podem reproduzir aspectos da vida real. Por mais que estejam ensimesmados e concentrados numa tarefa, é improvável que sintam medo, desejo, ansiedade e sentimentos como na vida real. Difícil que escutem os sons, sintam os cheiros, percebam os lugares".

Diante disso, o que resta é um convite para ousar, ir além, como muitos cientistas nos incentivariam a fazer. "O próprio Galileu", afirma o autor, "te- 
ria nos incentivado a não permanecermos religiosamente fiéis a suas ideias", mas, ao contrário, "a aprender mais, se houver algo mais para aprender".

Aqui está o convite à navegação em mar aberto por parte do autor, que em sua premissa intitulada A aposta (o livro se subdivide em cinco capítulos, e premissa e conclusão) estabelece alguns pontos firmes para prosseguir viagem. Maldonato mostra que o que está em jogo nessa "aposta" é muito mais do que a mera descrição de expressões de superfície de nosso cérebro (como raciocínios, decisões, intuição etc.) ou a representação da vida inconsciente como o lado sombrio da consciência. Em poucas páginas chega-se à conclusão de que o que realmente poderá marcar a diferença na pesquisa seria a (im)possiblidade de se estabelecer um limite entre o racional e o irracional. Especialmente porque, como se disse, a ideia comum de "racionalidade" é bastante falaciosa. E mesmo estabelecer um limiar claro entre certeza e incerteza é tarefa problemática. Maldonato convida, portanto, a novos debates, novas discussões. "Os recentes desdobramentos das ciências da decisão", diz, "já demoliram essa ideia de racionalidade, devolvendo centralidade a fatores decisivos como a imprevisibilidade e a incerteza", já que a análise dos comportamentos reais mostrou que decidimos quase sempre conforme esquemas simplificados, muitas vezes condicionados por representações e percepções distorcidas do risco: "Em certo sentido, a consciência toma ciência dos acontecimentos, mas não os produz. A relevância disso é que grande parte da vida da mente se desdobra fora da consciência e, sobretudo, que seu horizonte é enormemente mais vasto e profundo. A consciência se quebra na mente como uma onda de superfície, sem influenciar as correntezas profundas. Seus efeitos são tardios, fragmentos de um passado recente, experiências que já foram". E precisamos também, por exemplo, ter maior precisão conceitual com algumas "palavras-coringa". In primis, precisamente o termo "consciência" (um dos temas de exploração mais recorrentes em Maldonato) com seus variados significados conforme o setor que a utiliza, que por isso mesmo padece, nas palavras do autor, de uma "confusão terminológica secular". Assim, entre as distinções necessárias, o estudioso italiano inicia propondo aquela entre "mente" e "consciência", já que boa parte da vida da mente se desdobra fora daquele âmbito da consciência que significa "ciência", "conhecimento".

A progressão dos capítulos, como variações musicais sobre o mesmo tema, vai construindo o arcabouço teórico em que Maldonato se fundamenta para tecer suas considerações críticas, em um crescendo tão bem imbricado que, como mencionamos, permite acompanhar pari passu o pensamento do autor à medida que comenta, critica e amplia a esfera de uma determinada tese, aplicando-a sempre à sua experiência prática de clínica, ancorando-a em sua experiência do cotidiano, de maneira que o leitor consegue se reconhecer naquelas observações. 
"A mente é o corpo", afirma adiante Maldonato, quase acelerando o ritmo do raciocínio - ele próprio estimulado por aquele espírito de "busca crítica persistente e inquieta da verdade" que caracteriza o homem de ciência -, aquele corpo que "permanece como um texto a ser decifrado, a despeito das fascinações tecnocientíficas e de uma realidade virtual que engloba os nossos sentidos".

O que deve ser feito, portanto, é criar "algo inédito, uma operação que se livre daquele modelo de racionalidade que se espelha inteiramente na lógica": pensamentos, emoções, conceitos, sentimentos não ficam um do lado do outro, mas "um compenetrado no outro". O cérebro humano, descreve o autor, é um "sistema aberto que flutua entre dinâmicas distantes do equilíbrio", um sistema de instabilidade crescente que gera novas estruturas de ordem.

E a decisão humana só pode "emergir no desconhecido", de "processos que desafiam o pensamento", nos quais quem comanda mesmo é a incerteza. Assim a origem da decisão é quase sempre inconsciente: a (cons)ciência "se encarrega da decisão apenas a seguir, e parcialmente". Isso, porém, diz Maldonato, alargando o campo do pensamento, não quer dizer que a pessoa não seja responsável pelas próprias ações. Assim também deveria ser em âmbito judiciário: "Um indivíduo no qual tenham sido encontradas anomalias cerebrais, por meio de exames de escaneamento, não é sinônimo de um indivíduo incapaz de responsabilidade".

É um assunto pouco explorado fora do habitual contexto científico-acadêmico, e nesse (e para esse) âmbito mais amplo o texto se torna um convite a extrapolar os hábitos: Maldonato consegue ancorar assuntos e argumentos complexos e agudos para nosso simples dia a dia. Em uma época em que ainda sofremos os fascínios de uma suposta racionalidade e de um modelo de cérebro comparado a um computador (lembram-se da inteligência artificial?) esse escrito desmistifica muitos dos mitos que ainda vigoram e nos estimula, de um lado, a sermos mais curiosos e, de outro, a sermos mais críticos. Em todos os aspectos de nossa vida, ressalto. Levando em conta, no entanto, que nossos sentimentos e nossa irracionalidade desempenham um papel muito mais amplo do que sequer imaginamos ao longo de nossa vida, e que, ainda assim, um rastro genético de nossa espécie desempenha um papel essencial nesse modelo, porque foi o que nos permitiu evoluirmos e chegarmos até aqui.

O primeiro capítulo, O longo caminho da racionalidade, mostra como as nossas decisões, que como se disse acreditamos serem ditadas por nossa racionalidade, na verdade se fundamentam em ações ditadas por respostas adaptativas eficazes. Ao observar de perto o processo decisório, podemos inferir que a ideia de um equilíbrio entre razão e emoção, tão cara ao racionalismo iluminista, está longe de ser real. O autor vai além: quando um 
indivíduo, ou uma sociedade humana, utilizam plenamente as próprias capacidades, sempre tendem a alterar seus estados de equilíbrio, ou melhor "a criar um estado de permanente desequilíbrio". Das moléculas aos organismos, dos indivíduos às sociedades, nosso universo é um "arquipélago de sistemas no oceano da desordem".

No segundo capítulo, Antes da decisão, Maldonato ilustra como a incerteza, assim como o risco, a ambiguidade e a imprevisibilidade que a ela se vinculam, têm muito a ver com a decisão. Uma série de estudos teóricos e empíricos realizados a partir da segunda metade do século 20 mostrou a importância da maneira com que os indivíduos enfrentam riscos e incertezas. Mas por que motivo a incerteza é tão importante no estudo da decisão? Podemos conviver com ela de maneira razoável? Podemos conceber uma "lógica da incerteza"? Claro que as leis da probabilidade representam um novo meio de enfrentar a incerteza. Mas o que se observa no dia a dia é que as normas racionais são constantemente abandonadas e que o mundo está repleto de incoerências de comportamento e erros de cálculo. Isso seria uma tendência natural de nossa mente, ou ao contrário, a descrição de nossos processos decisórios é o que estaria inadequado e falacioso? Maldonato acredita que é necessário pensarmos uma nova descrição da mente, que inicie reconhecendo o papel fundamental que os estratagemas naturais para enfrentar com eficácia situações de incerteza desempenham. A dificuldade, em suma, não está dentro de nossa cabeça, mas fora dela. Já o terceiro capítulo, Movimento puro, ilustra o componente automático que habita quase todo gesto. E como uma criança que leva quase um ano para levantar-se e dar os primeiros passos e que, depois de algum tempo, vai andar com segurança devido à harmonia conquistada entre músculos e movimentos. A criança nem sabe como chegou a este ponto, mas daquele momento em diante, para ela, andar será a coisa mais natural do mundo. Especialmente os gestos certeiros apoiam-se em automatismos dos quais não temos ciência. Um músico experiente, afirma Maldonato, mostra claramente uma complexa interação entre aprendizado, elaboração temporal e execução: um pianista virtuose pode conversar tranquilamente enquanto seus dedos escorrem rápida e sincronicamente sobre as teclas. Mas um pianista experiente que durante semanas ou meses anda às voltas com a mesma partitura ignora o que seu cérebro está fazendo. Sabe apenas que vai encontrar muitas dificuldades se não executar aquele trecho inúmeras vezes. Então, a certa altura, deixará de refletir. Apoiar as mãos no teclado é o que bastará para que seus dedos escorram agilmente, com segurança. Obviamente a fluidez na execução não mascara uma plena presença na execução. Mas para que o músico pudesse expressar ao máximo sua personalidade artística, precisou criar automatismos. Nesse capítulo, com o eficaz (e pessoalmente sentido) exemplo musical, Mauro Maldonato mostra como, ao longo da vida, muitos de nossos gestos se tornam automáticos, para que então, superadas as dificuldades motoras, possamos dar pleno desenvolvimento a nossas potencialidades. E 
quem nunca passou por isso, por exemplo, ao aprender a dirigir com tanta dificuldade em coordenar movimentos e atenção (e tensão) e pouco mais tarde se descobrindo habilidoso e capaz de ter outros pensamentos que não sejam apenas o de evitar os outros carros?

No quarto capítulo, Inconsciência soberana, Maldonato fala de alguns experimentos que mostraram que há uma diferença temporal entre a execução de um gesto e a consciência (no sentido de ciência ou awareness) de que o executamos. O que significa, comenta Maldonato, "que o cérebro sabe antes do que nós que pretendemos agir, e a (cons)ciência da ação chega somente depois que realizamos aquela ação". Quem reina é a inconsciência. O autor vai nos mostrando que nossa ideia de um Eu (cons)ciente, o Eu como fluxo, na verdade é apenas o eco de uma sensação de viver em continuidade, uma sequência de momentos isolados que percebemos como a passagem de ritmos naturais. Em suma, o nosso Eu é um desdobramento incessante e vital de estados que se equilibram entre um não mais e um não ainda. E, mais uma vez, estamos tocando um tema sensível do autor, a questão do instante e do fluxo, em uma só palavra, da temporalidade e do homem lidando com ela. Finalmente, no quinto capítulo, Liberdade determinada, o autor discorre sobre ilações quanto à possível existência, sugerida por experimentos realizados nos últimos anos, de uma "neurobiologia da moral". Discute-se a possibilidade de que juízos morais se realizem em área distinta do cérebro daqueles julgamentos não morais.

Na verdade, a pergunta ainda carece de uma resposta definitiva. Mas se pode afirmar que no decorrer do desenvolvimento da espécie humana as emoções sociais permitiram que nossos ancestrais compreendessem os próprios similares e constituíssem sociedades cooperativas, criando assim o solo fértil para o surgimento de valores - e sistemas de valores - de instituições sociais, políticas e culturais compartilhadas. Assim dor, senso de justiça, autoridade, pureza, fazer parte de uma comunidade são todos aspectos cujas raízes evolucionais são profundas. E isso não diz respeito apenas ao homem. Sempre fundamentando suas observações em pesquisas científicas, Maldonato afirma que, por exemplo, o instinto de evitar a dor alheia está presente nos primatas; que o senso de justiça tem a ver com o altruísmo recíproco, desde que o ato seja sustentável para quem o realiza e que quem o recebe esteja disposto a retribuir; que o respeito pelas autoridades tem a ver com as hierarquias de domínio e submissão; que o senso de comunidade que impele os indivíduos a compartilhar e se sacrificarem por uma finalidade impessoal poderia derivar da empatia e da solidariedade para com os consanguíneos e não consanguíneos.

Finalmente, na conclusão, Despedida, o autor constata um reconhecimento cada vez mais amplo quanto à natureza complexa de nosso cérebro, reafirmando, assim, que esse fato exige ainda mais uma mudança de perspecti- 
va. O cérebro é cada vez menos descrito como um computador, composto por circuitos pré-fabricados pelos genes. O fato de esse nosso órgão ter-se constituído progressivamente, por meio de sofisticados processos de seleção natural, o torna bem distante de um conjunto genético cerebral. As múltiplas competições seletivas e criativas em seu interior criaram, ao longo da evolução biológica de nossa espécie, vínculos com o ambiente físico, social e cultural. À diferença do que acontecia até algumas décadas o cérebro humano nos parece hoje um sistema aberto, em flutuação, como se disse, entre dinâmicas bem distantes do equilíbrio: um sistema exposto o tempo todo a vínculos internos e dinâmicas externas que geram níveis crescentes de instabilidade, que, por sua vez, criam novas estruturas de ordem. Nesta altura, o autor, ironicamente, diz desconfiar que por conjura da natureza as leis cerebrais internas tenham sido planejadas para desviar o tempo todo o observador do rumo certo. Ainda assim, este fato não compromete nossa sede de conhecimento, antes, estimula cada um a se perguntar se não seria o caso de inaugurar novos métodos de exploração.

Por isso, Na hora da decisão: somos seres conscientes ou máquinas biológicas? estimula que indaguemos perspectivas pouco habituais, propondo uma ideia de racionalidade limitada: tomar uma decisão é apenas parcialmente um processo consciente, porque naquele "sistema aberto" que é o nosso cérebro, a soberania invisível do inconsciente também desempenha seu belo papel. "Um pensamento vem quando ele quer, não quando eu quero": a partir desse relato de uma cena vivida pelo autor em sua prática clínica, e da aflição relatada pelo paciente por não poder dominar seu pensamento, Maldonato explica que a questão da decisão passou a intrigá-lo desde então, o que explica seu constante "corpo a corpo" com a região desconhecida, a presença misteriosa que chamamos de "consciência".

Mas então, qual a resposta? Somos "máquinas biológicas" ou "atores" cientes? Talvez sejamos ambas as coisas, ou nenhuma das duas, se as entendermos assim como as entendemos até então.

Desmistificando ainda mais nossas convicções, em entrevista recente ${ }^{2}$, Maldonato afirma: "A ilusão de controle da realidade produziu inquietude, ansiedade, doenças psicossomáticas. Se os fármacos mais vendidos são hoje ansiolíticos e antidepressivos, isso que dizer que nosso modelo não é apropriado ao homem, mas, ao contrário, se trata de um modelo abstrato que gera mal-estar. As neurociências nos dizem que tudo o que fazemos são ações preditivas, que de algum modo antecedem a consciência. Um esquiador, um tenista, agem com base em percepção e antecipação, sempre abaixo do limiar da consciência [no sentido de ciência]. Mas mesmo um enxadrista, cuja performance leva tempos bem mais longos, não pode confiar totalmente no raciocínio: se desse para calcular as infinitas variantes causadas por cada movimento de uma peça no tabuleiro, ficaria paralisado 
e sem dúvida iria em direção a uma derrota. Se do Rift Valley, o ponto de partida do homo sapiens, chegamos ao Silicon Valley, o lugar da máxima modernidade e inovação tecnológica, foi graças à nossa capacidade adaptativa e a decisões rápidas (como apanhar uma presa, como fugir de um predador) que pouco têm a ver com a consciência racional.

A decisão, portanto, é um processo da vida psíquica do qual participam racionalidade, intuito, fatores biológicos, normas culturais, desejos inconscientes. Ela aflora no desconhecido, de processos que desafiam nosso pensamento. O livro de Maldonato nos descortina um universo inteiro de hipóteses, conjeturas, possíveis modelos. Nenhum deles é o definitivo, sabe-se, mas nosso dever, salienta o autor, é continuar buscando. "Gosto de pensar" - conclui Maldonato - que essas tentativas possam se tornar "pistas para outras explorações", considerando que nossos conhecimentos atuais são apenas parciais, daí o convite a "ousarmos mais", a soltarmos as amarras, pois "é necessária uma noção mais eficaz do inconsciente para dar um nome àquele algo que age em nós e que, erroneamente, o homem se ilude que possui; aquele algo que acreditamos ser Eu".

\section{Notas}

${ }^{1}$ Da orelha da obra em italiano, Quando Decidiamo. Firenze: Giunti Editore, 2015.

${ }^{2}$ FIORE, Antonio. A Lacco Ameno Maldonato e il fantasma della razionalità. Corriere del Mezzogiorno, 31 jul. 2015.

\section{Roberta Barni}

Professora Doutora no Departamento de Letras Modernas da Faculdade de Filosofia, Letras e Ciências Humanas da Universidade de São Paulo (USP) e tradutora literária. De Mauro Maldonato traduziu inúmeras obras ao português; ente elas, a obra em análise. E-mail: rbarni@usp.br 